\title{
Modification of acidic and textural properties of a sulphated zirconia catalyst for efficient conversion of high-density polyethylene into liquid fuel
}

Almustapha, Muhammad N.; Farooq, Muhammad; Mohammed, Misbahu L.; Farhan, Muhammad; Imran, Muhammad; Andresen, John M.

\section{Published in:}

Environmental science and pollution research international

Link to article, DOI:

$10.1007 / \mathrm{s} 11356-019-04878-9$

Publication date:

2020

Document Version

Peer reviewed version

Link back to DTU Orbit

Citation (APA):

Almustapha, M. N., Farooq, M., Mohammed, M. L., Farhan, M., Imran, M., \& Andresen, J. M. (2020). Modification of acidic and textural properties of a sulphated zirconia catalyst for efficient conversion of highdensity polyethylene into liquid fuel. Environmental science and pollution research international, 27, 55-65. https://doi.org/10.1007/s11356-019-04878-9

\section{General rights}

Copyright and moral rights for the publications made accessible in the public portal are retained by the authors and/or other copyright owners and it is a condition of accessing publications that users recognise and abide by the legal requirements associated with these rights.

- Users may download and print one copy of any publication from the public portal for the purpose of private study or research.

- You may not further distribute the material or use it for any profit-making activity or commercial gain

- You may freely distribute the URL identifying the publication in the public portal 


\title{
Modification of Acidic and Textural Properties of a Sulphated Zirconia Catalyst for Efficient Conversion of High-Density Polyethylene into Liquid Fuel
}

\author{
Muhammad N. Almustapha ${ }^{1,2}$, Muhammad Farooq ${ }^{* 1,3}$, Misbahu L. Mohammed ${ }^{2}$, Muhammad \\ Farhan $^{3}$, Muhammad Imran ${ }^{4}$, John M. Andresen ${ }^{1}$
}

${ }^{1}$ Research Centre for Carbon Solutions, Institute of Mechanical, Process and Energy Engineering, Heriot-Watt University, UK

${ }^{2}$ Department of Pure and Applied Chemistry, Usmanu Danfodiyo University, Sokoto Nigeria.

${ }^{3}$ Department of Mechanical Engineering, University of Engineering and Technology Lahore, KSK Campus, Pakistan

${ }^{4}$ Department of Mechanical Engineering, Technical University of Denmark, Denmark

*Corresponding author Email: mf181@hw.ac.uk / engr.farooq@uet.edu.pk

\begin{abstract}
Consumption of plastic has rapid increase of about $8 \%$ per annum and reached to 400 million per tonnes approximately, where about $50 \%$ plastic was disposed after using only once. Different techniques for treating this increased waste faced number of issues related to cost, environmental and sustainable development. Catalytic conversion has been found as one of the most viable solution to solve this problem. Sulphated zirconia (SZ) catalyst modified with calcium Carbide (CC) was found to improve HDPE conversion into liquids fuel. The liquid content was improved from $39.0 \mathrm{wt} \%$ to $66.0 \mathrm{wt} \%$ at $410^{\circ} \mathrm{C}$. HDPE was converted $100 \%$ by weight using, SZ/CC with $66 \mathrm{wt} \%$ liquid yield as compared to the conversion of approximately $98 w t \%$ with about $40 w t \%$ only liquid yield for the pure SZ. The composition of hydrocarbon liquid product was significantly changed from paraffin (16\%) and aromatic (58\%) to olefin (74\%) and naphthenic (23\%) compounds. This significant increase in liquid was related to changes in the acidic and textural characteristics of the new hybrid catalyst, SZ/CC where the total ammonia desorption of $337.0 \mu \mathrm{mNH}_{3} / \mathrm{g}$ for the $\mathrm{SZ}$ was modified to $23.4 \mu \mathrm{mNH}_{3} / \mathrm{g}$ for the SZ/CC. Both SZ and SZ/CC catalysts showed characteristics of mesoporous material, where the internal pore volume of $S Z$ had reduced from $0.21 \mathrm{~mL} / \mathrm{g}$ for $S Z$ to $0.04 \mathrm{~mL} / \mathrm{g}$ for $S Z / C C$. Furthermore, XRD analysis indicated the presence of a new compound, $\mathrm{CaZrO}_{3}$ in the $\mathrm{SZ} / \mathrm{CC}$, which confirmed a chemical interaction between the $\mathrm{SZ}$ and $\mathrm{CC}$ through sintering of $\mathrm{ZrO}_{2}$ and $\mathrm{CaO}$. Therefore, the SZ/CC catalyst improves the liquid yield significantly and the selectivity towards olefinic and naphthenic compounds
\end{abstract}


Key words - Catalytic conversion, sulphated zirconia, calcium carbide, HDPE, plastic waste

\section{Introduction}

Consumption of plastics, in particular high density polyethylene (HDPE), has increased at-least $8 \%$ each year since the 1950 s, which is predicted as to reach 322 and 405 million tonnes by the years 2015 and 2018, respectively, where about $50 \%$ of plastic is disposed after using only one time as usual practice (Hopewell et al., 2009; Panda et al., 2010; Reddy et al., 2013; Singhabhandhu \& Tezuka, 2010). Although various recycling methods have been applied to manage plastic waste, many of these have practical, environmental and economic limitations (Farooq et al., 2018; Huang et al., 2010; Keane, 2009; Lin et al., 1998; Lin \& Yen, 2005; Miskolczi et al., 2009; Shah et al., 2010a; Shent et al., 1999; Zadgaonkar, 2004). Chemical recycling has been suggested as a viable option for plastic waste management when using a suitable catalyst to convert plastic waste into valuable hydrocarbon products (Aguado et al., 2008; Al-Salem et al., 2009; Almustapha et al., 2017; Miskolczi et al., 2006; Panda et al., 2010; Singhabhandhu \& Tezuka, 2010; Walendziewski \& Steininger, 2001; Wei et al., 2010). Unlike the products obtained from thermal conversion, which requires upgrading, the hydrocarbon product using catalytic conversion have the capacity to be used as feedstock or fuel for different industrial processes (Keane, 2009; Lin et al., 1998; López et al., 2011; Shah et al., 2010a; Shah et al., 2010b). Various catalysts, in particular basic and acidic zeolites, have been tested but few have resulted in both high conversions and high liquid yield with selectivity towards desirable hydrocarbon components (Arandes et al., 2007; Gobin \& Manos, 2004a; Gobin \& Manos, 2004b; Huang et al., 2010; Lin \& Yen, 2005; López et al., 2011; Saha et al., 2008; Serrano et al., 2000a; Serrano et al., 2007; Shah et al., 2010a; Tarrío-Saavedra et al., 2011). Recently, it was found that sulphated zirconia showed excellent catalytic activity toward HDPE recycling at temperatures below $400^{\circ} \mathrm{C}$ where a conversion of over $99 \mathrm{wt} \%$ with liquid and gas yields of $34 \mathrm{wt} \%$ and $66 \mathrm{wt} \%$, respectively, was reported (Almustapha \& Andrésen, 2012). Sulphated zirconia is one of the best catalyst for oil refining techniques, however, it needs wide spread in the literature for plastic conversion (Ahmed et al., 2008; Arata et al., 2003; Clark, 2002; Hino et al., 2006; Yadav \& Nair, 1999). One of the best characteristics of SZ catalyst are related to its good acidity, chemical as well as thermal stability. However, sulphated zirconia was found to promote aromatic compounds similar to that widely reported for zeolites (Almustapha \& Andrésen, 2012; Saha et al., 2008; Serrano et al., 2000b). This study has focused on achieving this by modifying the textural as well as acidic characteristics 
of the SZ with the mixing of CC to promote liquid yield as high and impede secondary reactions leading to aromatics as demonstrated in the work reported Shah et al. (2010a). The saturated and aromatic compounds have previously worked well with zeolites and are proposed for the first time here with the sulphated zirconia (Elordi et al., 2009; López et al., 2011; Marcilla et al., 2009; Serrano et al., 2007; Sharratt et al., 1997).

\section{Experimental}

\subsection{Materials and Catalyst Preparation}

High density poly-ethylene (HDPE) in pellet form (about $3 \mathrm{~mm}$, and melt index of 42 grams) was used. The HDPE particle size was reduced to $0.25-0.05 \mathrm{~mm}$ using a SM2000 Retch Mill. Different characteristics includes proximate and elemental compositions of the HDPE sample are listed in Table 1. A commercial sulphated zirconia catalyst (XZO 1248, $\approx 7 \mathrm{~mol}^{2} \mathrm{SO}_{3}$ ) with the size of the particle range of $100-150 \mu \mathrm{m}$. The hybrid catalyst SZ/CC was prepared by mechanically mixing the sulphated zirconia and calcium carbide at a ratio of $1: 1$. The mixture was calcined in air at $550^{\circ} \mathrm{C}$ for four hours using a Type 1500 Thermo Scientific Barnstead /Thermolyne Compact Benchtop Muffle Furnace.

Table 1. Proximate and Elemental Composition of the High-Density Polyethylene

\begin{tabular}{|c|c|c|c|c|c|c|c|}
\hline \multicolumn{3}{|c|}{ Proximate composition* \% } & \multicolumn{5}{|c|}{ Elemental analysis (\%) } \\
\hline $\begin{array}{l}\text { Fixed } \\
\text { carbon }\end{array}$ & $\begin{array}{c}\text { Ash } \\
\text { content }\end{array}$ & $\begin{array}{c}\text { Volatile } \\
\text { matter }\end{array}$ & Carbon & Hydrogen & Nitrogen & Oxygen & Sulphur \\
\hline 3.2 & 0.0 & 96.8 & 85.7 & 14.3 & 0.0 & 0.0 & 0.0 \\
\hline
\end{tabular}

* dry basis

\subsection{Catalyst characterisations}

SEM (Scanning Electron Microscopy-FEI 600F version 2.4) was used for the surface morphology of the SZ catalyst. Elemental and oxide analysis were conducted to find the elemental composition of particles. The XRD powder patterns were received with the help of a Hilton-brooks DG which was operated at 20mA with 40Kv Philips PW 1000 goniometer approx. Scanning speed of 2 degree (20) per minute was conducted with a range about 5-60 degree and a step size of $0.05^{\circ}$. The textural characteristics of the SZ catalyst including the surface area and porosity were determined using the Micrometrics Gemini-VII. A Quantachrome Chem-BET TPR/TPD instrument was fitted for data analysis to carry out the $\mathrm{NH}_{3}$ temperature programmed desorption (TPD) for measurement of acidic strength of the catalyst. 


\subsection{HDPE conversion procedure}

Figure 1 explains the fixed bed system of stainless-steel tube $(2.2 \mathrm{~cm} \mathrm{ID,} 45 \mathrm{~cm} \mathrm{~L})$ installed for the catalyst conversion of HDPE. A programmable temperature controller furnace was used to provide a uniform heat and mass transfer along the reactor. The run was conducted with equal amount (roughly $5 \mathrm{~g}$ each) of HDPE and catalyst placed into an alumina crucible and inserted into the stainless-steel tube reactor. The $\mathrm{N}_{2}$ was purged in the tube with $30 \mathrm{cl} / \mathrm{min}$ for about half hour prior to heating and during heating at $20^{\circ} \mathrm{C}$ per minute from ambient to $410^{\circ} \mathrm{C}$, where the system was held for $30 \mathrm{~min}$ before it was cooled to the room standard temperature. The product yields were calculated using Equation 1 according to previous published methods (Aguado et al., 2007; Lin \& Yen, 2005; Miskolczi et al., 2009).

$$
\text { Yield }(w t \%)=\frac{W_{p}}{W_{r}} X 100
$$

Where, $\mathrm{W}_{\mathrm{p}}$ is the weight of products (liquid and gas) and $\mathrm{W}_{\mathrm{r}}$ is the weight of reactants

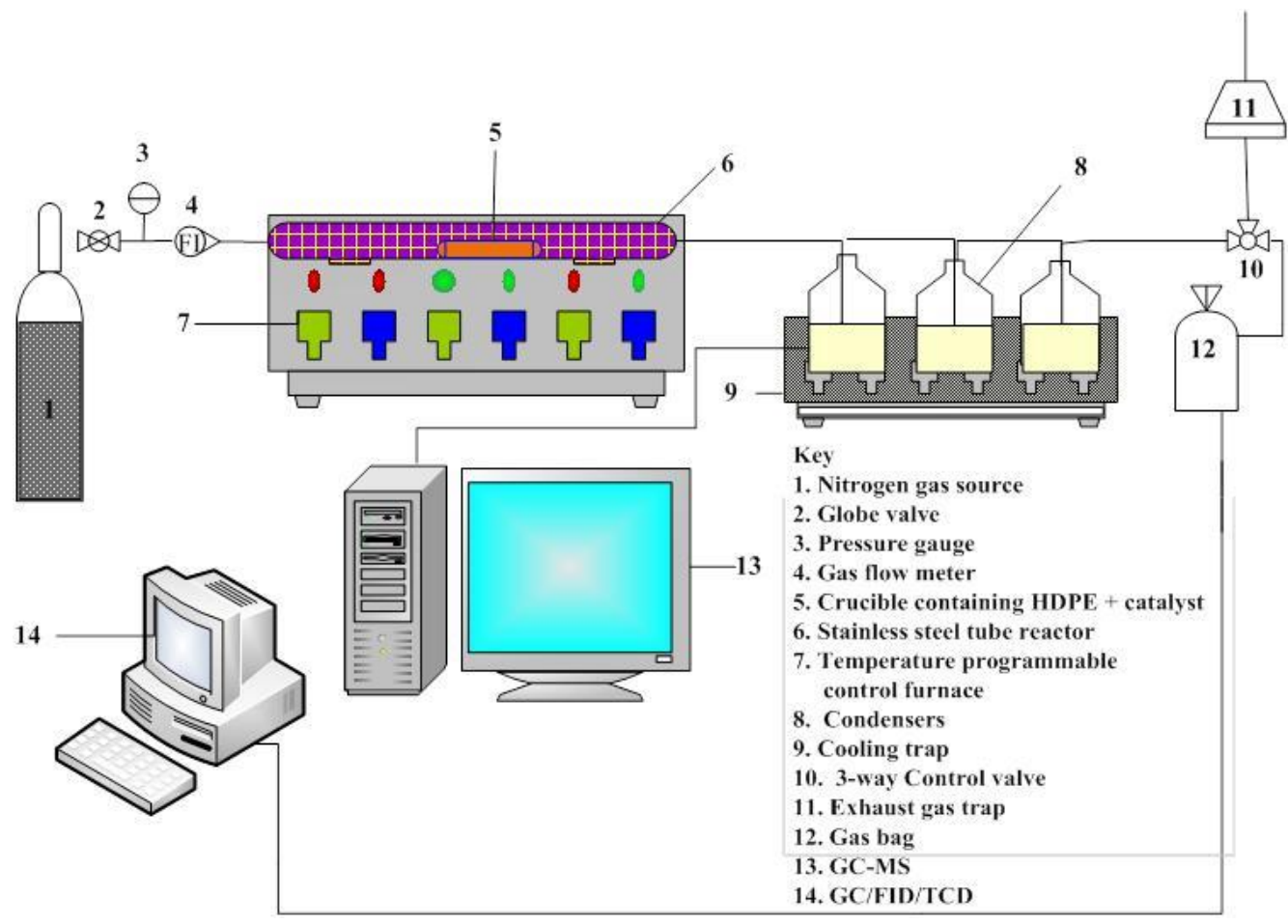

Figure 1. Fixed-bed reactor for the catalytic conversion into liquid fuel 


\subsection{Product analysis}

Hydrocarbon composition of the liquid yield was analysed with $70 \mathrm{eV}$ ionising energy at $280^{\circ} \mathrm{C}$. A column of silica capillary was used for the separation which was coated with BPX5 phase. Helium gas with a 2 min hold at $50^{\circ} \mathrm{C}$ was used as carrier gas, which was then increased to $300^{\circ} \mathrm{C}$ with $5^{\circ} \mathrm{C} \mathrm{min}^{-1}$ and kept for about half hour. The analyses of gaseous yields with a flame ionization detector were conducted with an initial hold for $13 \mathrm{~min}$ at $60^{\circ} \mathrm{C}$ and further increased to $160^{\circ} \mathrm{C}$ with $10^{\circ} \mathrm{C} \mathrm{min}^{-1}$ and kept for about 15 minutes.

\section{Results and discussion}

\subsection{Catalyst analysis for HDPE conversion}

Table 2 compares the HDPE conversion of the SZ with that of the new hybrid catalyst SZ/CC. Calcium carbide on its own did not show any conversion and was not included. The liquid yield for the new hybrid catalyst SZ/CC was $66 \mathrm{wt} \%$ indicating a significant improvement compared to $39 \mathrm{wt} \%$ in the presence of the pure SZ. Also, the gas and unconverted residue have all reduced significantly to $<0.1$ and $34 \mathrm{wt} \%$ compared to $2 \mathrm{wt} \%$ and $59 \mathrm{wt} \%$, respectively. The liquid obtained using the hybrid catalyst SZ/CC had a composition of $74 \mathrm{wt} \%$ olefin, $23 \mathrm{wt} \%$ naphthens, $3 \mathrm{wt} \%$ paraffins and $<0.1 \mathrm{wt} \%$ aromatics. However, there is a significant change from the pure SZ, where the liquid composed of highest proportion of aromatic (58wt\%). This indicates by adding CC, the catalytic activity of the pure SZ has modified to support high liquid output. Figure 2 compares the hydrogen and hydrocarbon compositions of the gas fractions obtained in the presence of the pure SZ and the hybrid catalyst SZ/CC. The gaseous fraction obtained in the presence of SZ contained more saturated hydrocarbons and low hydrogen compared to that of the hybrid catalyst SZ/CC, which promoted mainly olefins particularly C5, $\mathrm{C} 4$ and $\mathrm{C} 3$. This composition is same and in-lined with the liquid obtained using these catalysts. The results indicate that SZ promoted the formation of aromatics and perhaps generates a surplus of hydrogen, which could have been used to form more saturated hydrocarbon compounds in the gas phase. However, this was not the case for the hybrid catalyst SZ/CC, where an unzipping of the structure took place leaving olefinic compounds both in the gas and liquid phases. 
Table 2. Comparison of conversion, liquid and gas yields

\begin{tabular}{|l|c|c|}
\hline & Sulphated zirconia (SZ) & Calcium carbide modified SZ \\
\hline Total conversion (\%) & 98.0 & 100 \\
\hline Residue (wt\%) & 2.0 & 0 \\
\hline Total liquid yield (wt\%) & $\mathbf{3 9 . 0}$ & $\mathbf{6 6 . 0}$ \\
\hline Olefins (\%) & 21.0 & 74.0 \\
\hline Naphthens (\%) & 5.0 & 23.0 \\
\hline Paraffins (\%) & 16.0 & 3.0 \\
\hline Aromatics (\%) & 58.0 & $<0.1$ \\
\hline Total Gas yield (wt\%) & $\mathbf{5 9 . 0}$ & $\mathbf{3 4 . 0}$ \\
\hline
\end{tabular}

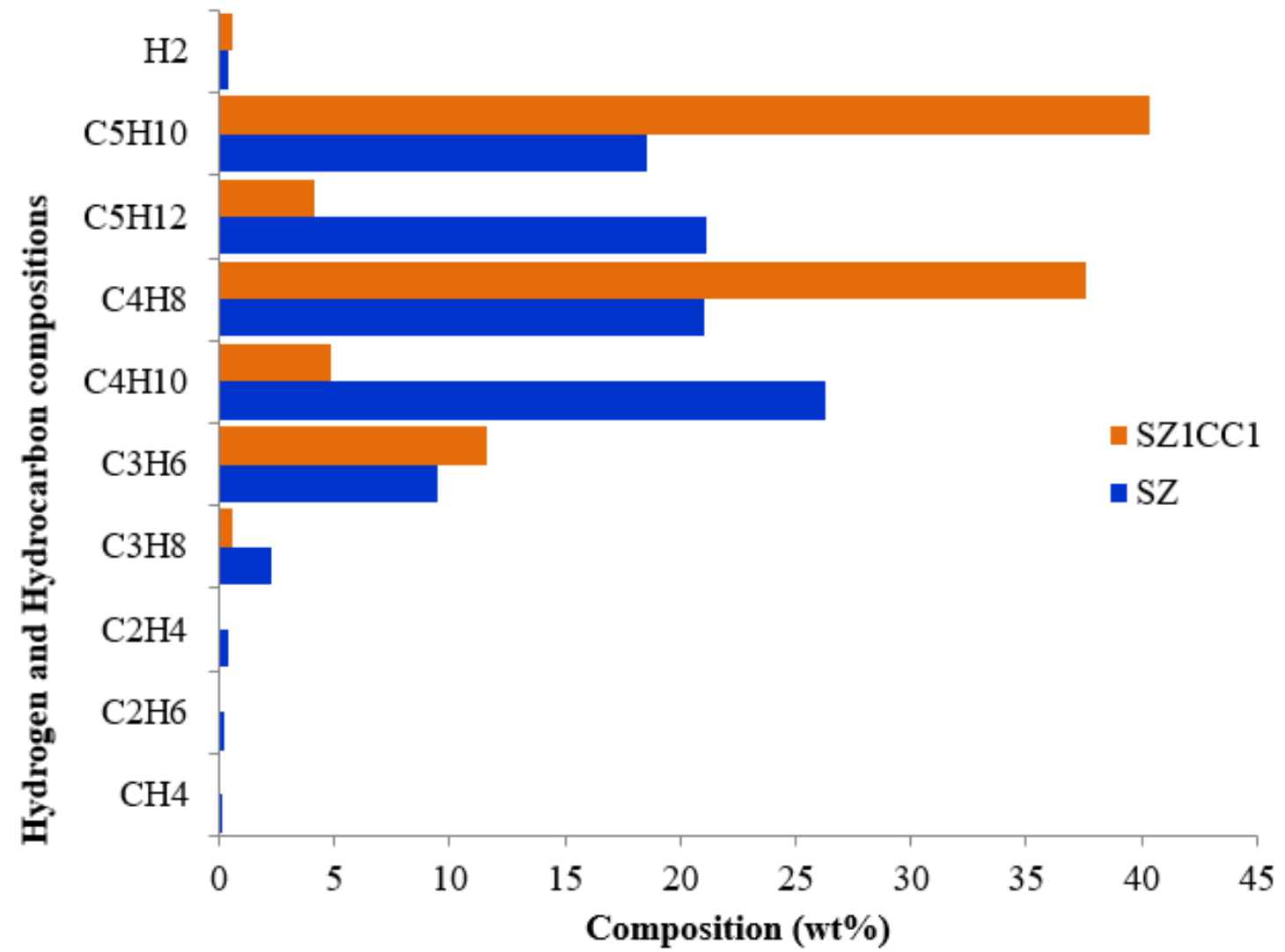

Figure 2. Hydrogen and Hydrocarbon compositions of the gaseous fraction

\subsection{Catalyst Characterisation}

Table 3 summarised and compared the acidic strength and total ammonia desorption of the pure SZ, the calcined CC and the hybrid catalyst SZ/CC obtained from $\mathrm{NH}_{3}-\mathrm{Temperature-}$ Programmed Desorption (TPD) spectra. The $\mathrm{NH}_{3}$-TPD spectra were classified into three temperature regions, as, $200-350^{\circ} \mathrm{C}$ (a), $350-550^{\circ} \mathrm{C}$ (b) and above $550^{\circ} \mathrm{C}$ (c). Since the desorption was owing to physisorption, so it was discontinued before $200^{\circ} \mathrm{C}$ (Elordi et al., 2009; Katada et al., 1997; López et al., 2011; Shi \& Li, 2013; Zhao et al., 2008). Pure SZ had three acid sites at temperatures of maximum desorption of $230^{\circ} \mathrm{C}, 365^{\circ} \mathrm{C}$ and $640^{\circ} \mathrm{C}$. The hybrid 
catalyst SZ/CC and the calcined CC had only two desorption peaks at $294^{\circ} \mathrm{C}$ and $541^{\circ} \mathrm{C}$ for the SZ/CC and $371^{\circ} \mathrm{C}$ and $542^{\circ} \mathrm{C}$ for calcined CC, respectively. This shows that acidic strengths are normal, strong as well as very strong for the SZ, which co-inside with the published literature (Barthos et al., 2001; Oh et al., 2011; Zhao et al., 2008). But, the peak above $550^{\circ} \mathrm{C}$, which indicates very strong acidic strength was completely absent in both the hybrid catalysts SZ/CC and calcined CC. The SZ seems to have the highest ammonia desorption of $337.0 \mu \mathrm{molNH}_{3} / \mathrm{g}$ but reduced to $23.4 .0 \mu \mathrm{molNH}_{3} / \mathrm{g}$ for hybrid catalyst SZ/CC. The calcined $\mathrm{CC}$ on its own had ammonia desorption of $45.923 .4 \mu \mathrm{mmolNH}_{3} / \mathrm{g}$. The increased ammonia desorption observed in calcined $\mathrm{CC}$ at $350-550^{\circ} \mathrm{C}$ is attributed largely to ammonia adsorbed by $\mathrm{CaO}$ (Yang et al., 2012). Overall, the high acidic strength and total ammonia desorption could be responsible for the cracking ability of the catalyst. In the presence of the hybrid catalyst SZ/CC with the total ammonia desorption of only $23.4 .0 \mu \mathrm{molNH}_{3} / \mathrm{g}$ of only strong acidity, the liquid yield increased to $66.0 \mathrm{wt} \%$ compared to only $39.0 \mathrm{w} \%$ for the SZ, which has high total ammonia desorption of $337.0 \mu \mathrm{molNH}_{3} / \mathrm{g}$ with both strong and very strong acidities. This is expected since catalysts with high acidic strength generally give excessive cracking that leads to high gas yields (Angyal et al., 2009; López et al., 2011; Miskolczi et al., 2004). Calcined calcium carbide on its own with $44.4 \mu \mathrm{molNH}_{3} / \mathrm{g}$ did not affect the HDPE conversion even though with about twofold ammonia desorption than the hybrid catalyst SZ/CC. This because the ammonia desorption by the calcined $\mathrm{CC}$ was due ammonia adsorbed by $\mathrm{CaO}$ not by acid sites of the catalyst, thus, provided very little HDPE cracking.

Table 3 Analysis of the NH3 desorbed with acidic strength for SZ, hybrid catalyst SZ/CC and the calcined $\mathrm{CC}$ from curve-fitted $\mathrm{NH}_{3}$-TPD spectra

\begin{tabular}{|c|c|c|c|c|}
\hline \multirow{2}{*}{ Catalysts } & \multicolumn{4}{|c|}{$\mathrm{NH}_{3}$ desorbed $(\mu \mathrm{molNH} / \mathrm{g})$} \\
\hline & $200-300$ & $300-550$ & $>\mathbf{5 5 0}$ & Total $\mathrm{NH}_{3}$ desorbed \\
\hline SZ & 142.0 & 158.5 & 37.1 & 337.6 \\
\hline SZ/CC & 2.8 & 20.6 & nd & 23.4 \\
\hline $\mathrm{CC}$ & 1.4 & 44.4 & nd & 45.8 \\
\hline
\end{tabular}

nd: not detected

\subsection{Comparison of SEM micrograph and EDX spectrum of the pure SZ}

Figure 3 compares the SEM micrographs and EDX spectra of the SZ, the hybrid catalyst SZ/CC and the calcined CC. The SEM images showed that the SZ, the calcined CC and the hybrid 
catalyst SZ/CC have same particle size (100nm to 200nm). The SZ particles appeared less clustered and contained many open pores as illustrated by circles A while the CC particles appeared highly clustered as indicated by circles C. However, the particles of hybrid catalyst SZ/CC appear clustered but with few open pores as indicated by circles B. The SEM image of SZ/CC indicated that the open pore structure in the SZ was blocked by the particle of calcium carbide. The pore volume and surface area of the hybrid catalyst could get reduced as outlined in Table 4, which shows that the hybrid catalyst SZ/CC had $0.04 \mathrm{~cm}^{3} / \mathrm{g}, 23.1 \mathrm{~m}^{2} / \mathrm{g}$ and $22.2 \mathrm{~m}^{2} / \mathrm{g}$ as pore volume, BET and external surface areas, respectively. These characteristics are much lower than those of pure SZ, which had $0.21 \mathrm{~cm}^{3} / \mathrm{g}, 116.0 \mathrm{~m}^{2} / \mathrm{g}$ and $112.0 \mathrm{~m}^{2} / \mathrm{g}$ as pore volume, BET and externals surface areas, respectively. This reveals that by adding CC has significantly reduced the pore volume, BET and external surface areas of the new catalyst as suggested by SEM results. The reduction in pore volume also lead to the reduction of internal porosity in the hybrid catalyst, where the micropore area is reduced from $3.9 \mathrm{~m}^{2} / \mathrm{g}$ to $<0.1 \mathrm{~m} 2 / \mathrm{g}$. The pore size has also significantly reduced from $10.8 \mathrm{~nm}$ for SZ to 8.2 and 5.0 for the hybrid catalyst and calcined CC, respectively. The EDX spectra showed that in SZ there are peaks indicating the zirconium predominance and large portion of oxygen while in CC carbon predominates with substantial amount of oxygen. However, in SZ/CC calcium appeared predominant with large portion of zirconium and substantial amount of oxygen This show that mixing sulphated zirconia with calcium carbide has led to significantly change in the textural and physicochemical properties of the new SZ/CC catalyst.

Table 4 Comparison of characteristics of the SZ, the calcined CC and the hybrid catalyst $\mathrm{SZ} / \mathrm{CC}$.

\begin{tabular}{|l|c|c|c|}
\hline Characteristics & SZ & SZ/CC & CC \\
\hline BET total surface area $\left(\mathrm{m}^{2} / \mathrm{g}\right)$ & 116.0 & 23.1 & 10.2 \\
\hline External surface area $\left(\mathrm{m}^{2} / \mathrm{g}\right)$ & 112.0 & 22.2 & 8.7 \\
\hline Micropore volume $\left(\mathrm{cm}^{3} \mathrm{~g}^{-1}\right)$ & 0.0013 & $\mathrm{nd}$ & $\mathrm{nd}$ \\
\hline Micropore area $\left(\mathrm{m}^{2} / \mathrm{g}\right)$ & 3.90 & $<0.1$ & $<0.1$ \\
\hline pore volume $\left(\mathrm{cm}^{3} \mathrm{~g}^{-1}\right)$ & 0.21 & 0.04 & 0.012 \\
\hline Average pore size $(\mathrm{nm})$ & 10.8 & 8.2 & 5.0 \\
\hline
\end{tabular}



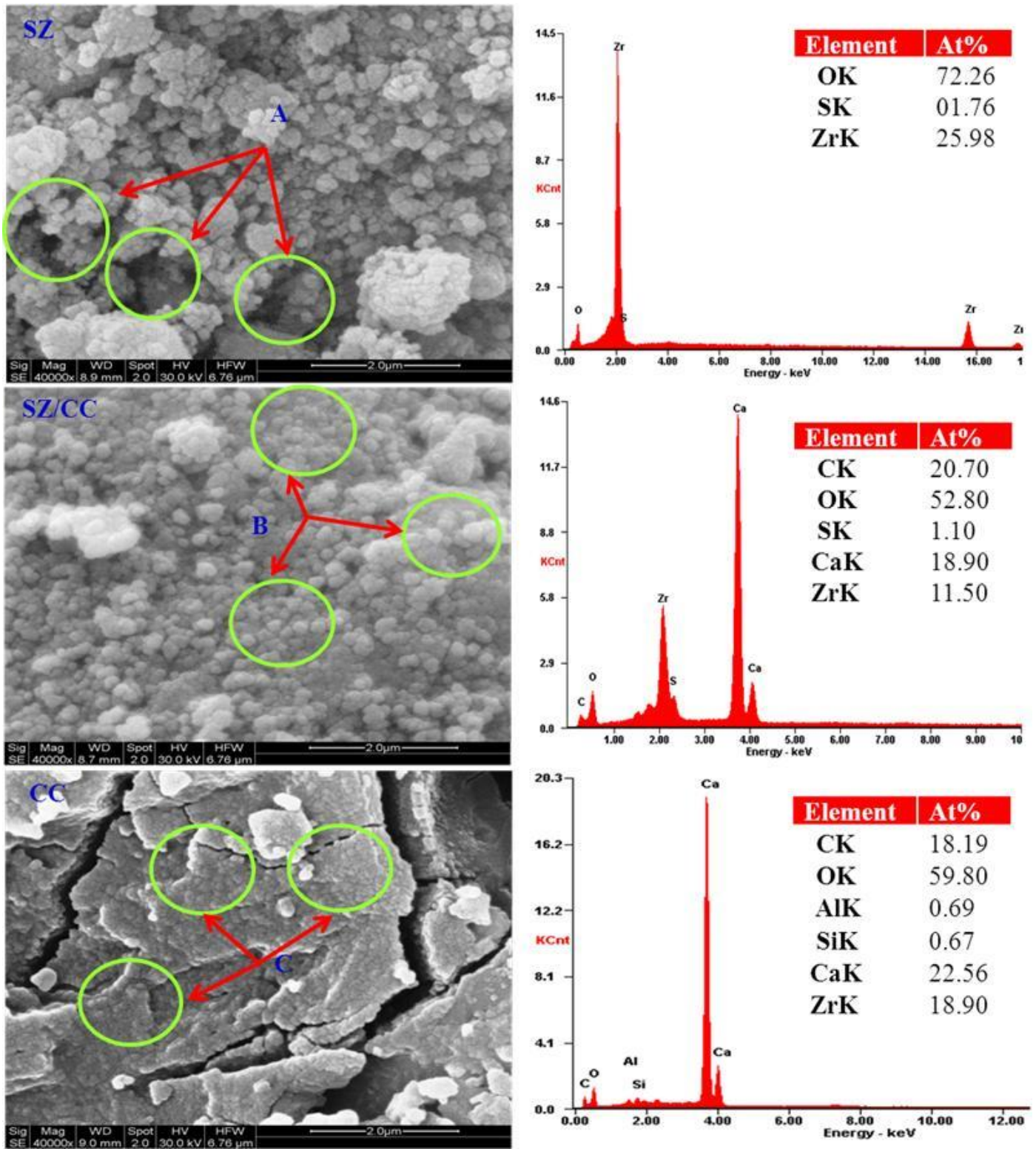

Figure 3 Comparison of SEM micrograph and EDX spectrum of the pure SZ, the hybrid catalyst SZ/CC and the CC calcium carbide after calcination at $550^{\circ} \mathrm{C}$.

\subsection{Comparison of nitrogen adsorption isotherms}

Figure 4 compares the $\mathrm{N}_{2}$ adsorption isotherms of the pure $\mathrm{SZ}$, hybrid catalyst $\mathrm{SZ} / \mathrm{CC}$ and the calcined CC. The shape of the adsorption isotherms of all the three catalysts resemble that of Type IV isotherm (Donohue \& Aranovich, 1999). However, the nitrogen absorption was more prominent in the SZ than SZ/CC and calcined CC. The SZ had the highest nitrogen adsorption of about $1.10 \mathrm{mmol} / \mathrm{g}$ at low relative pressure $\left(\mathrm{P} / \mathrm{P}^{\mathrm{o}}<0.1\right)$ than the hybrid catalyst $\mathrm{SZ} / \mathrm{CC}$ and calcined CC with 0.22 and $0.10 \mathrm{mmol} / \mathrm{g}$, respectively. This indicated some level of micropores in SZ, which reduced in the hybrid catalyst SZ/CC and virtually none in the calcined CC as evidenced by the nitrogen adsorbed at low relative pressure $\left(\mathrm{p} / \mathrm{p}^{0}<0.01\right)($ Serrano et al., 2007). 
This indicates that the overall porosity of sulphated zirconia has significantly reduced in hybrid catalyst SZ/CC after addition of calcium carbide. This again corroborated with SEM and BET results, which showed overall reduction of porosity and surface area after $\mathrm{CC}$ addition.

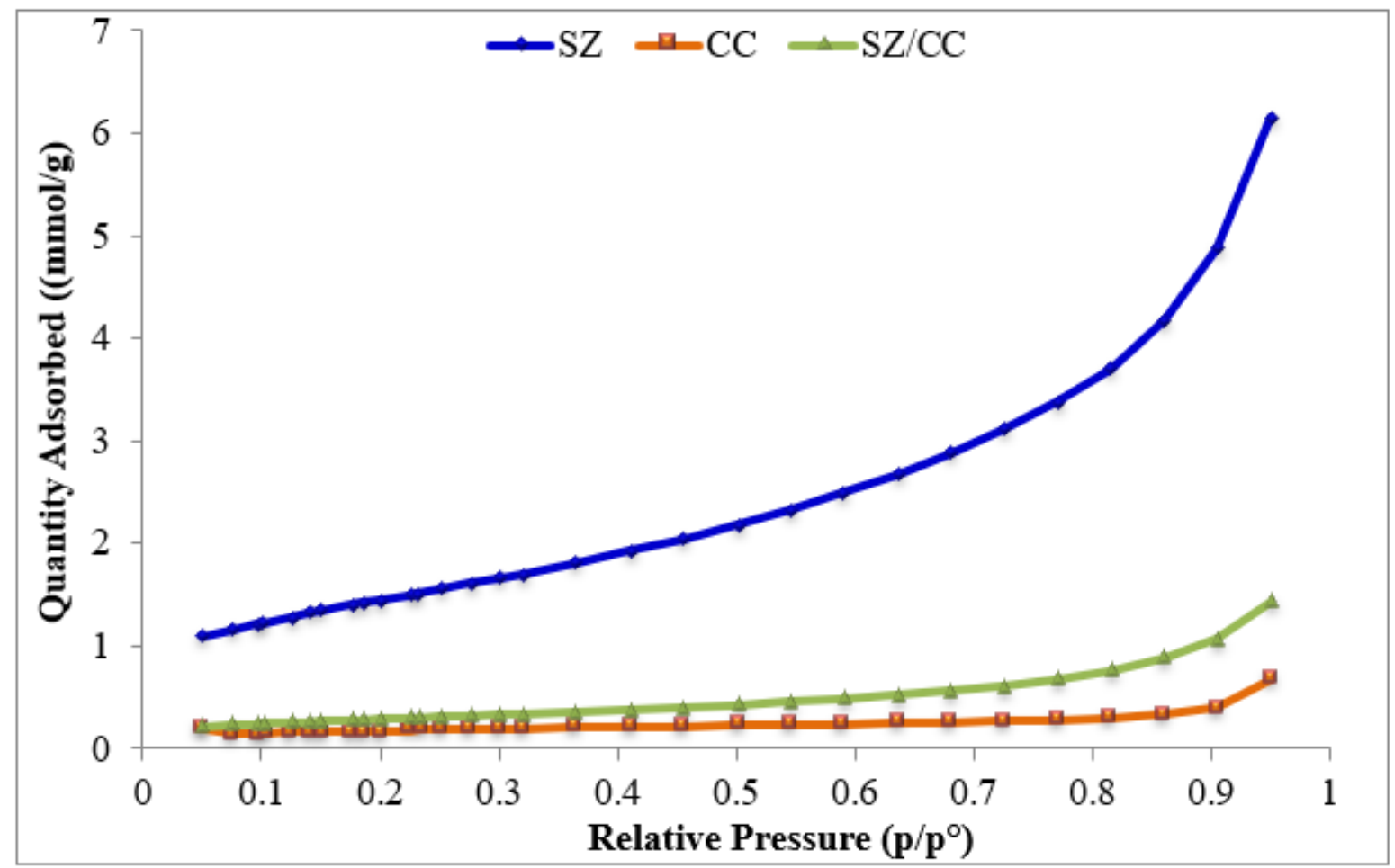

Figure 4 Comparison of $\mathrm{N}_{2}$ isotherms of the SZ, the hybrid catalyst SZ/CC and the calcined CC.

\subsection{Pore size distribution using BHJ method}

Figure 5 shows the distribution of the pores with respect to size for the SZ catalyst, the calcined $\mathrm{CC}$ and hybrid catalysts SZ/CC. It has been revealed from the results as presented in the figure that all the samples with size from 1.5 to $12 \mathrm{~nm}$ has broad distribution of pores. This depicts the mesoporous structure of the particles, since these falls mostly from $2 \mathrm{~nm}$ to $12 \mathrm{~nm}$. This behaviour validate the presence of mesoporous particles in all samples as described in the $\mathrm{N}_{2}$ isotherm in Figure 5 (Mishra et al., 2003; Rezaei et al., 2006). 


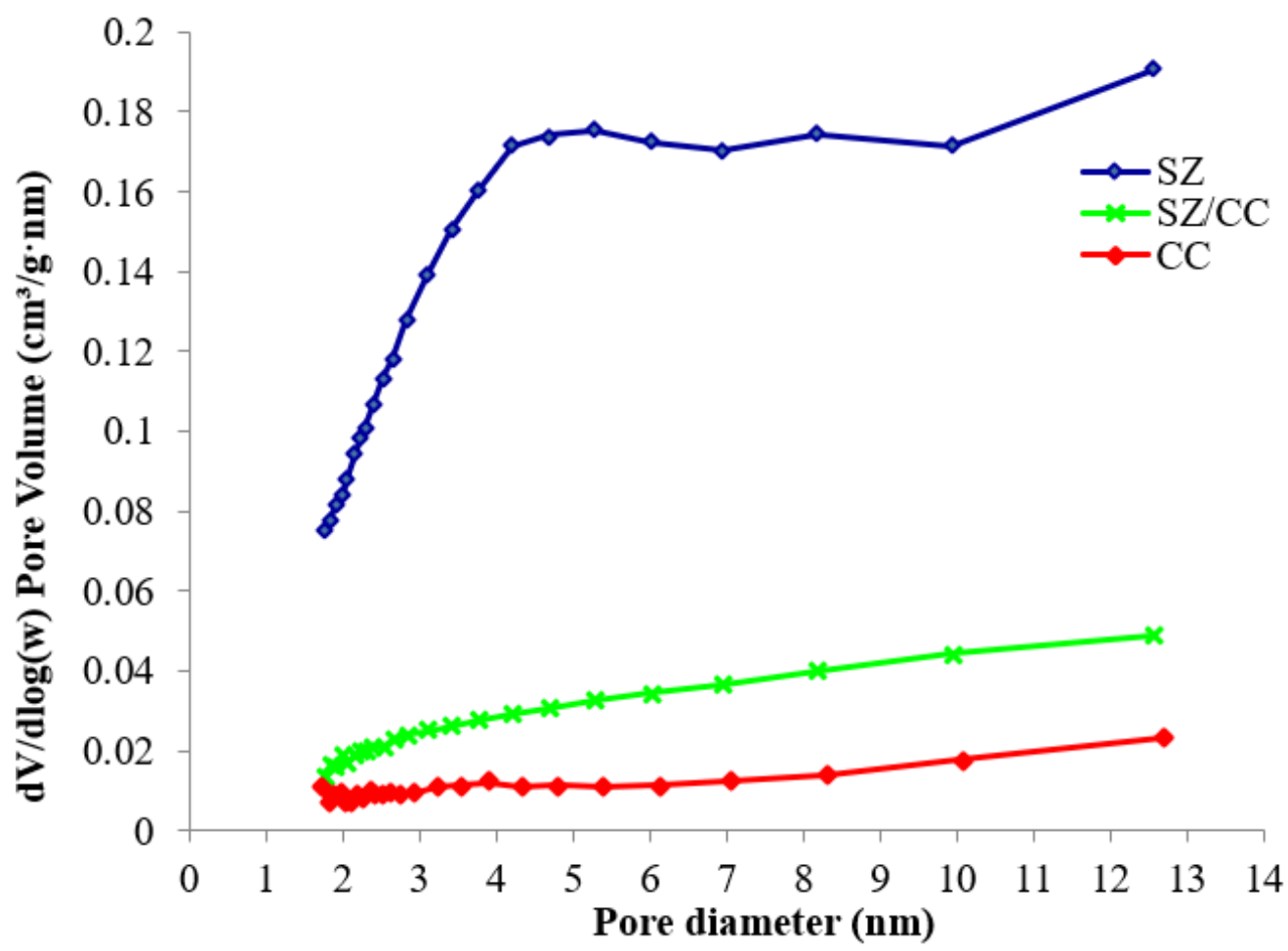

Figure 5 Pore size distributions of the SZ, the $\mathrm{CC}$ and the hybrid catalysts SZ4CC1 to SZ1CC4 using BJH method

Table 5 compares bulk elemental and oxide compositions of the catalysts obtained from EDX. The hybrid catalyst SZ/CC indicated the increase of $\mathrm{CaO}$ (27.7 Mol\%) and $\mathrm{CaCO}_{3}(44.4 \mathrm{Mol} \%)$ against $<0.1 \mathrm{Mol} \%$ each in pure SZ. However, the $\mathrm{SO}_{3}(2.4 \mathrm{Mol} \%)$ and $\mathrm{ZrO}_{2}(25.5 \mathrm{Mol} \%)$ in the hybrid catalyst SZ/CC were considerably low compared to $6.6 \mathrm{Mol} \%$ and $93.36 \mathrm{Mol} \%$ for sulphated zirconia and $<0.1 \mathrm{Mol} \%$ but higher than that of the calcined CC. This particularly for $\mathrm{SO}_{3}$, is in line with 1 total ammonia desorption of $23.4 \mu \mathrm{molNH} / \mathrm{g}$ for the hybrid catalyst SZ/CC indicating a significant reduction compared to the $\mathrm{SZ}$ with $337.0 \mu \mathrm{molNH}_{3} / \mathrm{g}$. This further confirmed that addition of calcium carbide has significantly modified the acidic strength of the hybrid catalyst, which significantly enhanced the conversion and liquid yield.

Table 5 Bulk compositions of the SZ, the calcined CC and hybrid catalyst SZ/CC.

\begin{tabular}{|l|c|c|c|}
\hline Surface compositions & $\begin{array}{c}\text { Sulphated zirconia } \\
\text { (SZ) }\end{array}$ & $\begin{array}{c}\text { Hybrid catalyst } \\
(\text { SZ/CC) }\end{array}$ & $\begin{array}{c}\text { Calcium carbide } \\
\text { (CC) }\end{array}$ \\
\hline $\mathrm{SO}_{3}(\mathrm{Mol} \%)^{\mathrm{e}}$ & 6.6 & 2.4 & $<0.1$ \\
\hline $\mathrm{ZrO}_{2}(\mathrm{Mol} \%)^{\mathrm{e}}$ & 93.36 & 25.5 & $<0.1$ \\
\hline $\mathrm{CaO}(\mathrm{Mol} \%)^{\mathrm{e}}$ & $<0.1$ & 27.7 & 53.1 \\
\hline $\mathrm{CaCO}(\mathrm{Mol} \%)^{\mathrm{f}}$ & $<0.1$ & 44.4 & 46.9 \\
\hline
\end{tabular}

${ }^{\mathrm{e}} \mathrm{EDX}$

${ }^{\mathrm{f}} \mathrm{EDX}$ (by difference) 


\subsection{Comparison of the powder XRD diffraction pattern}

Figure 6 shows the powder XRD patterns of the pure SZ, the calcined CC and the hybrid catalyst SZ/CC. The SZ appeared to have four major peaks $(\bullet)$ contained tetragonal $\mathrm{ZrO}_{2}$ (JCPD no. 50-1089) observed at $2 \theta=30.41$ (relative intensity is 100) as well as 35.25 (20), 50.71(52) and 60.28 (31). These set of peaks were still observed from the hybrid catalyst SZ/CC with only additional phase of compound indexed $\mathrm{CaZrO}_{3}$ (JCPD no. 48-0904). The new particles of the new complex compound $\left(\mathrm{CaZrO}_{3}\right)$ formed probably blocked the open pores observed in pure SZ. This again reaffirmed the suggestion that addition of the CC could affect the selectivity of the catalyst by reducing accessibility to internal acid site which allows secondary reaction leading to aromatic formation.
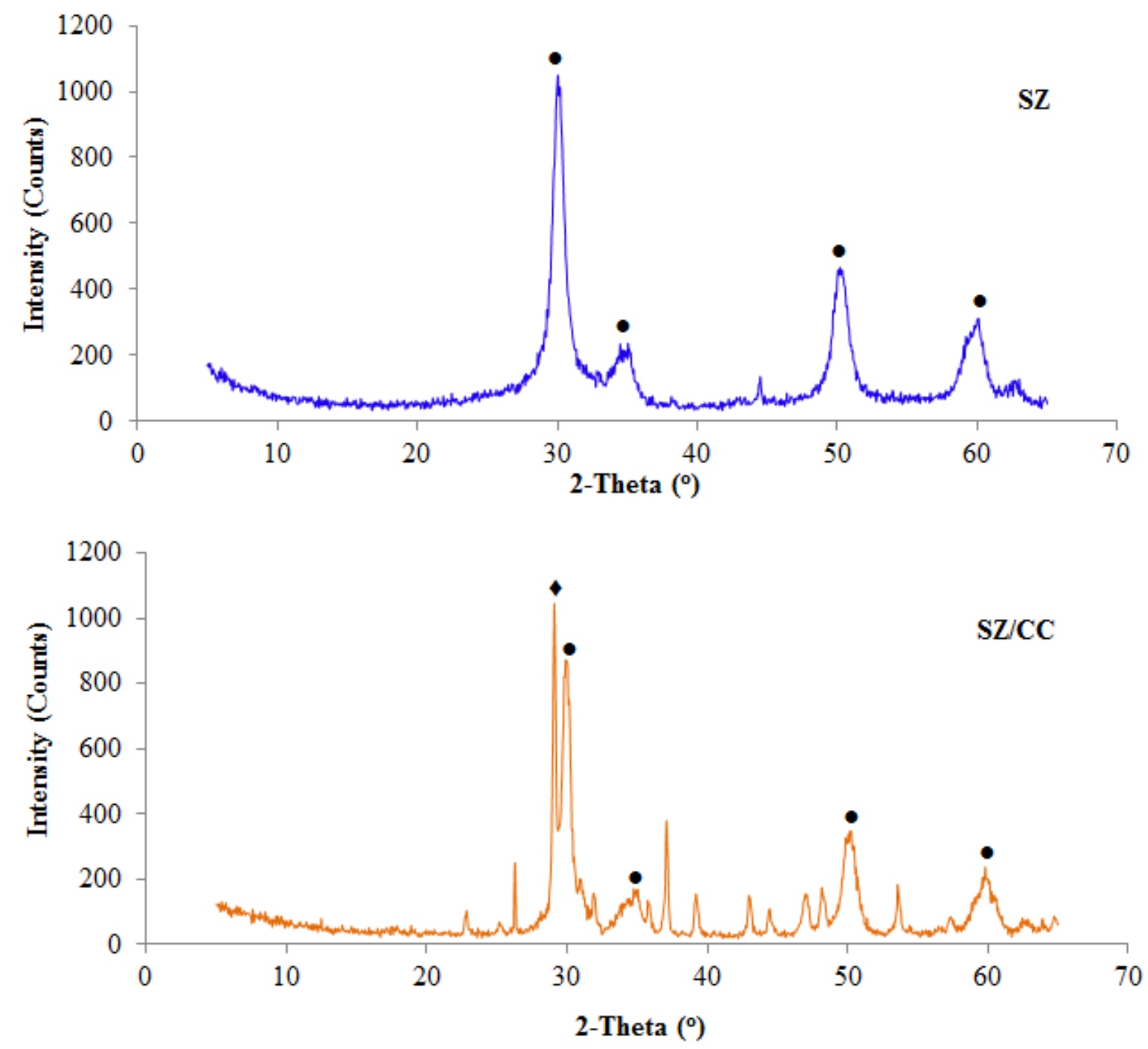

Figure 6. Comparison of the powder XRD diffraction pattern of the sulphated zirconia (SZ) and hybrid version (SZ/CC). 


\subsection{Summary of the characteristics of pure SZ and hybrid catalyst, SZ/CC and their catalytic activities towards HDPE conversation.}

Figure 7 highlighted the summary characteristics of the pure SZ and the new hybrid catalyst SZ/CC and results outcome of their performance towards HDPE conversion. Pure SZ showed low liquid yield, which contains large aromatic compounds, while the new hybrid catalyst gave high liquid yield that contains high proportion of olefinic and naphthenic hydrocarbon compounds. The changes in the liquid yield and selectivity shown by the new hybrid catalyst were linked with the changes in the physicochemical compositions, acidic strength and textural properties of the new hybrid catalyst SZ/CC. As catalysts with strong acidity are mainly in gaseous state and hence very low liquid yields (Akpanudoh et al., 2005; Angyal et al., 2009; Hernandez et al., 2006; Liu \& Smith, 2008; López et al., 2011; Miskolczi et al., 2004; Saha et al., 2008). Also catalysts with large surface area and porosity give easy accessibility to the internal acid site due to less diffusional coerce and promote secondary reactions such as aromatisation and yield aromatic compounds as seen in pure SZ (Aguado et al., 2009; Marcilla et al., 2009; Serrano et al., 2007; Sharratt et al., 1997).

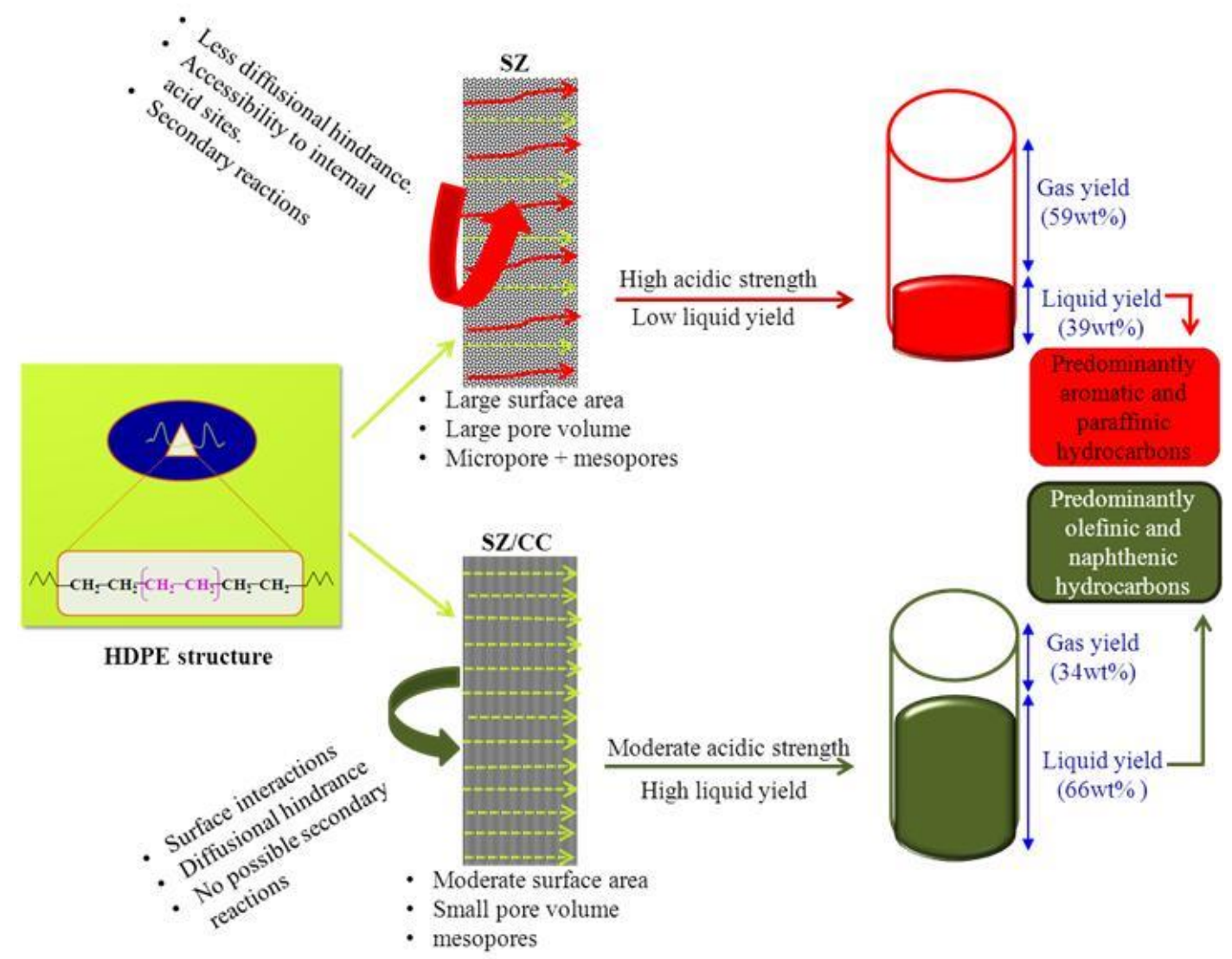

Figure 7. Summary of the properties of pure SZ and hybrid catalyst, SZ/CC and their catalytic activities towards HDPE conversion. 


\section{Conclusion}

A commercial sulphated zirconia catalyst was modified with calcium carbide and the resulting hybrid catalyst, SZ/CC showed improved catalytic activity and selectivity for HDPE conversation into low-aromatic liquids. Catalytic conversion of HDPE using the new hybrid catalyst revealed a significant increase in liquid yield of $66.0 \mathrm{wt} \%$ compared to only $39.0 \mathrm{wt} \%$ of the pure SZ. The unconverted residue and gaseous product decreases from $2.0 \mathrm{wt} \%$ and $59.0 \mathrm{wt} \%$ for the pure SZ to $<0.1 \mathrm{wt} \%$ and $34.0 \mathrm{wt} \%$, respectively. Various catalysts characterisation techniques revealed that the physicochemical, textural and acidic properties of the catalyst have changed significantly after addition of calcium carbide. The BET and external surface area as well as pore volume have reduced significantly $116,1120 \mathrm{~m}^{2} / \mathrm{g}, 0.2 \mathrm{~cm}^{3}$ for the $\mathrm{SZ}$ to $24.0 \mathrm{~m}^{2} / \mathrm{g}, 23.0 \mathrm{~m}^{2} / \mathrm{g}$ and $0.04 \mathrm{~cm}^{3}$, respectively. Acidic strength has also been modified from very strong for pure the SZ to strong for the new hybrid catalyst SZ/CC. The liquid and gaseous product compositions have also changed significantly in the presence of the hybrid catalyst SZ/CC. The hydrocarbon composition of liquid fraction in particular was changed from $58 \mathrm{vol} \%$ aromatic and $16 \mathrm{vol} \%$ paraffin dominated to $74 \%$ olefin and $23 \%$ naphthenic hydrocarbon compounds dominated. Hence, the efficient performance of new hybrid catalyst is strongly linked with the modification of textural properties and moderation of acidic strength due to calcium carbide addition.

\section{Acknowledgments}

The Authors remain indebted to MEL Chemicals and equally thankful to Petroleum Technology Devlopment Fund for providing sponsorship for the $\mathrm{PhD}$. We are also thankful to Professor Mercedes Maroto-Valer in whose laboratory some of the analyses were conducted.

\section{References}

1. Aguado, J., Serrano, D.P., Escola, J.M. 2008. Fuels from Waste Plastics by Thermal and Catalytic Processes: A Review. Industrial \& Engineering Chemistry Research, 47(21), 7982-7992.

2. Aguado, J., Serrano, D.P., Escola, J.M., Peral, A. 2009. Catalytic cracking of polyethylene over zeolite mordenite with enhanced textural properties. Journal of Analytical and Applied Pyrolysis, 85(1-2), 352-358.

3. Aguado, J., Serrano, D.P., Vicente, G., Sánchez, N. 2007. Enhanced Production of $\alpha$ Olefins by Thermal Degradation of High-Density Polyethylene (HDPE) in Decalin 
Solvent: Effect of the Reaction Time and Temperature. Industrial \& Engineering Chemistry Research, 46(11), 3497-3504.

4. Ahmed, A.I., El-Hakam, S.A., Samra, S.E., El-Khouly, A.A., Khder, A.S. 2008. Structural characterization of sulfated zirconia and their catalytic activity in dehydration of ethanol. Colloids and Surfaces A: Physicochemical and Engineering Aspects, 317(1-3), 62-70.

5. Akpanudoh, N.S., Gobin, K., Manos, G. 2005. Catalytic degradation of plastic waste to liquid fuel over commercial cracking catalysts - Effect of polymer to catalyst ratio/acidity content. Journal of Molecular Catalysis a-Chemical, 235(1-2), 67-73.

6. Al-Salem, S.M., Lettieri, P., Baeyens, J. 2009. Recycling and recovery routes of plastic solid waste (PSW): A review. Waste Management, 29(10), 2625-2643.

7. Almustapha, M.N., Andrésen, J.M. 2012. Recovery of Valuable Chemicals from High Density Polyethylene (HDPE) Polymer: a Catalytic Approach for Plastic Waste Recycling. International Journal of Environmental Science and Development, 3(3), 263-267.

8. Almustapha, M.N., Farooq, M., Andresen, J.M. 2017. Sulphated zirconia catalysed conversion of high density polyethylene to value-added products using a fixed-bed reactor. Journal of Analytical and Applied Pyrolysis, 125, 296-303.

9. Angyal, A., Miskolczi, N., Bartha, L., Valkai, I. 2009. Catalytic cracking of polyethylene waste in horizontal tube reactor. Polymer Degradation and Stability, 94(10), 1678-1683.

10. Arandes, J.M., Azkoiti, M.J., Torre, I., Olazar, M., Castano, P. 2007. Effect of HZSM5 catalyst addition on the cracking of polyolefin pyrolysis waxes under FCC conditions. Chemical Engineering Journal, 132(1-3), 17-26.

11. Arata, K., Matsuhashi, H., Hino, M., Nakamura, H. 2003. Synthesis of solid superacids and their activities for reactions of alkanes. Catalysis Today, 81(1), 17-30.

12. Barthos, R., Lónyi, F., Onyestyák, G., Valyon, J. 2001. An NH3-TPD and -FR study on the acidity of sulfated zirconia. Solid State Ionics, 141-142, 253-258.

13. Clark, J.H. 2002. Solid Acids for Green Chemistry. Accounts of Chemical Research, 35(9), 791-797.

14. Donohue, M.D., Aranovich, G.L. 1999. A new classification of isotherms for Gibbs adsorption of gases on solids. Fluid Phase Equilibria, 158-160(0), 557-563. 
15. Elordi, G., Olazar, M., Lopez, G., Amutio, M., Artetxe, M., Aguado, R., Bilbao, J. 2009. Catalytic pyrolysis of HDPE in continuous mode over zeolite catalysts in a conical spouted bed reactor. Journal of Analytical and Applied Pyrolysis, 85(1-2), 345-351.

16. Farooq, M., Almustapha, M., Imran, M., Saeed, M., Andresen, J.M. 2018. In-situ regeneration of activated carbon with electric potential swing desorption (EPSD) for the H2S removal from biogas. Bioresource technology, 249, 125-131.

17. Gobin, K., Manos, G. 2004a. Polymer degradation to fuels over microporous catalysts as a novel tertiary plastic recycling method. Polymer Degradation and Stability, 83(2), 267-279.

18. Gobin, K., Manos, G. 2004b. Thermogravimetric study of polymer catalytic degradation over microporous materials. Polymer Degradation and Stability, 86(2), 225-231.

19. Hernandez, M.D., Garcia, A.N., Gomez, A., Agullo, J., Marcilla, A. 2006. Effect of residence time on volatile products obtained in the HDPE pyrolysis in the presence and absence of HZSM-5. Industrial \& Engineering Chemistry Research, 45(26), 87708778 .

20. Hino, M., Kurashige, M., Matsuhashi, H., Arata, K. 2006. The surface structure of sulfated zirconia: Studies of XPS and thermal analysis. Thermochimica Acta, 441(1), $35-41$.

21. Hopewell, J., Dvorak, R., Kosior, E. 2009. Plastics recycling: challenges and opportunities. Philosophical Transactions of the Royal Society B: Biological Sciences, 364(1526), 2115-2126.

22. Huang, W.C., Huang, M.S., Huang, C.F., Chen, C.C., Ou, K.L. 2010. Thermochemical conversion of polymer wastes into hydrocarbon fuels over various fluidizing cracking catalysts. Fuel, 89(9), 2305-2316.

23. Katada, N., Igi, H., Kim, J.-H. 1997. Determination of the Acidic Properties of Zeolite by Theoretical Analysis of Temperature-Programmed Desorption of Ammonia Based on Adsorption Equilibrium. The Journal of Physical Chemistry B, 101(31), 5969-5977.

24. Keane, M.A. 2009. Catalytic Transformation of Waste Polymers to Fuel Oil. Chemsuschem, 2(3), 207-214.

25. Lin, Y.H., Sharratt, P.N., Garforth, A.A., Dwyer, J. 1998. Catalytic conversion of polyolefins to chemicals and fuels over various cracking catalysts. Energy \& Fuels, 12(4), 767-774.

26. Lin, Y.H., Yen, H.Y. 2005. Fluidised bed pyrolysis of polypropylene over cracking catalysts for producing hydrocarbons. Polymer Degradation and Stability, 89(1), 101108. 
27. Liu, X., Smith, K.J. 2008. Acidity and deactivation of Mo2C/HY catalysts used for the hydrogenation and ring opening of naphthalene. Applied Catalysis A: General, 335(2), 230-240.

28. López, A., de Marco, I., Caballero, B.M., Laresgoiti, M.F., Adrados, A., Aranzabal, A. 2011. Catalytic pyrolysis of plastic wastes with two different types of catalysts: ZSM5 zeolite and Red Mud. Applied Catalysis B: Environmental, 104(3-4), 211-219.

29. Marcilla, A., Beltrán, M.I., Navarro, R. 2009. Thermal and catalytic pyrolysis of polyethylene over HZSM5 and HUSY zeolites in a batch reactor under dynamic conditions. Applied Catalysis B: Environmental, 86(1-2), 78-86.

30. Mishra, M.K., Tyagi, B., Jasra, R.V. 2003. Effect of Synthetic Parameters on Structural, Textural, and Catalytic Properties of Nanocrystalline Sulfated Zirconia Prepared by Sol-Gel Technique. Industrial \& Engineering Chemistry Research, 42(23), 5727-5736.

31. Miskolczi, N., Angyal, A., Bartha, L., Valkai, I. 2009. Fuels by pyrolysis of waste plastics from agricultural and packaging sectors in a pilot scale reactor. Fuel Processing Technology, 90(7-8), 1032-1040.

32. Miskolczi, N., Bartha, L., Deak, G. 2006. Thermal degradation of polyethylene and polystyrene from the packaging industry over different catalysts into fuel-like feed stocks. Polymer Degradation and Stability, 91(3), 517-526.

33. Miskolczi, N., Bartha, L., Deák, G., Jóver, B., Kalló, D. 2004. Thermal and thermocatalytic degradation of high-density polyethylene waste. Journal of Analytical and Applied Pyrolysis, 72(2), 7.

34. Oh, J., Dash, S., Lee, H. 2011. Selective conversion of glycerol to 1,3-propanediol using Pt-sulfated zirconia. Green Chemistry, 13(8), 2004-2007.

35. Panda, A.K., Singh, R.K., Mishra, D.K. 2010. Thermolysis of waste plastics to liquid fuel A suitable method for plastic waste management and manufacture of value added products-A world prospective. Renewable \& Sustainable Energy Reviews, 14(1), 233248.

36. Reddy, M.M., Vivekanandhan, S., Misra, M., Bhatia, S.K., Mohanty, A.K. 2013. Biobased plastics and bionanocomposites: Current status and future opportunities. Progress in Polymer Science, 38(10-11), 1653-1689.

37. Rezaei, M., Alavi, S.M., Sahebdelfar, S., Yan, Z.-F. 2006. Tetragonal nanocrystalline zirconia powder with high surface area and mesoporous structure. Powder Technology, 168(2), 59-63.

38. Saha, B., Chowdhury, P., Ghoshal, A.K. 2008. Al-MCM-41 catalyzed decomposition of polypropylene and hybrid genetic algorithm for kinetics analysis. Applied Catalysis B: Environmental, 83(3-4), 265-276. 
39. Serrano, D.P., Aguado, J., Escola, J.M. 2000a. Catalytic conversion of polystyrene over HMCM-41, HZSM-5 and amorphous SiO2-Al2O3: comparison with thermal cracking. Applied Catalysis B-Environmental, 25(2-3), 181-189.

40. Serrano, D.P., Aguado, J., Escola, J.M. 2000b. Catalytic Cracking of a Polyolefin Mixture over Different Acid Solid Catalysts. Industrial \& Engineering Chemistry Research, 39(5), 1177-1184.

41. Serrano, D.P., Aguado, J., Rodriguez, J.M., Peral, A. 2007. Catalytic cracking of polyethylene over nanocrystalline HZSM-5: Catalyst deactivation and regeneration study. Journal of Analytical and Applied Pyrolysis, 79(1-2), 456-464.

42. Shah, J., Jan, M.R., Mabood, F., Jabeen, F. 2010a. Catalytic pyrolysis of LDPE leads to valuable resource recovery and reduction of waste problems. Energy Conversion and Management, 51(12), 2791-2801.

43. Shah, S.H., Khan, Z.M., Raja, I.A., Mahmood, Q., Bhatti, Z.A., Khan, J., Farooq, A., Rashid, N., Wu, D. 2010b. Low temperature conversion of plastic waste into light hydrocarbons. Journal of Hazardous Materials, 179(1-3), 15-20.

44. Sharratt, P.N., Lin, Y.H., Garforth, A.A., Dwyer, J. 1997. Investigation of the Catalytic Pyrolysis of High-Density Polyethylene over a HZSM-5 Catalyst in a Laboratory Fluidized-Bed Reactor. Industrial \& Engineering Chemistry Research, 36(12), 51185124.

45. Shent, H.T., Pugh, R.J., Forssberg, E. 1999. A review of plastics waste recycling and the flotation of plastics. Resources Conservation and Recycling, 25(2), 85-109.

46. Shi, W., Li, J. 2013. A New Deactivation Mechanism of Sulfate-Promoted Iron Oxide. Catalysis Letters, 143(12), 1285-1293.

47. Singhabhandhu, A., Tezuka, T. 2010. The waste-to-energy framework for integrated multi-waste utilization: Waste cooking oil, waste lubricating oil, and waste plastics. Energy, 35(6), 2544-2551.

48. Tarrío-Saavedra, J., Naya, S., Francisco-Fernández, M., Artiaga, R., Lopez-Beceiro, J. 2011. Application of functional ANOVA to the study of thermal stability of micro-nano silica epoxy composites. Chemometrics and Intelligent Laboratory Systems, 105(1), 114-124.

49. Walendziewski, J., Steininger, M. 2001. Thermal and catalytic conversion of waste polyolefines. Catalysis Today, 65(2-4), 323-330.

50. Wei, T.T., Wu, K.J., Lee, S.L., Lin, Y.H. 2010. Chemical recycling of post-consumer polymer waste over fluidizing cracking catalysts for producing chemicals and hydrocarbon fuels. Resources Conservation and Recycling, 54(11), 952-961. 
51. Yadav, G.D., Nair, J.J. 1999. Sulfated zirconia and its modified versions as promising catalysts for industrial processes. Microporous and Mesoporous Materials, 33(1-3), 148.

52. Zadgaonkar, A. 2004. Environmental Protection fron Plastic waste. in: GPEC, G.H. RAISONI COLLEGE OF ENGINEERING, NAGPUR, INDIA. NAHPUR, INDIA.

53. Zhao, J., Yue, Y., Hua, W., He, H., Gao, Z. 2008. Catalytic activities and properties of sulfated zirconia supported on mesostructured $\gamma$-A12O3. Applied Catalysis A: General, 336(1-2), 133-139.

54. Yang, X., Zhao, B., Zhuo, Y., Chen, C. \& Xu, X. The investigation of SCR reaction on sulfated CaO. Asia-Pacific Journal of Chemical Engineering, 2012, 7, 55-62 